\title{
Toughened Graphite-Epoxy Composites Exposed in Near-Earth Orbit for 5.8 Years
}

\author{
David K. Felbeck* \\ University of Michigan, Ann Arbor, Michigan 48109-2125
}

\begin{abstract}
This experiment was designed to measure the effect of near-Earth space exposure on three mechanical properties of specially toughened unidirectional T300/5208 graphite-epoxy cross-ply composite materials. The properties measured are fracture toughness, elastic modulus, and strength. Six toughness specimens and nine tensile specimens were mounted on an external frame during the 5.8-y orbit of the Long Duration Exposure Facility. Three identical sets of specimens were manufactured at the outset: the flight set, a zero-time nonflight set, and a total-time nonflight set. Results indicate that with proper protection from solar exposure and atomic-oxygen degradation, toughened graphite-epoxy composites can provide useful structural service in near-Earth orbit for at least five years.
\end{abstract}

\author{
Nomenclature \\ $E \quad=$ elastic modulus \\ $K_{\mathrm{I} c} \quad=$ mode-I critical stress intensity factor \\ $R \quad=$ fracture toughness \\ $S, S_{u} \quad=$ strength (tensile strength)
}

\section{Introduction}

$\mathbf{T}$ $\mathrm{HE}$ then-recent development of a procedure for improving the toughness of graphite-epoxy composites ${ }^{1,2}$ provided an appropriate material for near-Earth space exposure testing when the Long Duration Exposure Facility (LDEF) was publicly proposed by NASA Langley Research Center in the late 1970s. This toughening procedure, termed intermittent interlaminar bonding, consists in the introduction of a thin perforated layer of Mylar film between adjacent plies of a cross-ply composite so as to limit the area of inter-ply bonding. In this way, fracture of the composite is diverted when crossing regions having no bonding between plies, with a consequent substantial increase in total area of fracture and an increase in fracture energy, usually with only minor reduction in strength and elastic modulus. LDEF is a 12 -sided cylindrical frame roughly $9 \mathrm{~m}$ long and $4 \mathrm{~m}$ in diameter that was deployed with its axis perpendicular to the Earth's surface in a near-circular orbit inclined $28.5 \mathrm{deg}$ to the equator, and stabilized so that it did not rotate about its axis. The 11-month duration of LDEF, as originally planned, offered an opportunity to establish whether this composite would be suitable for structural applications in spacecraft. The mechanical properties of principal interest to the designer are fracture toughness, elastic modulus, and tensile strength, so these were the properties measured. That the orbit of LDEF lasted 5.8 years turned out to provide much more valuable results than would have been obtained in 11 months. With an orbital plane approximately $5 \mathrm{deg}$ from the ecliptic, LDEF was deployed from a shuttle orbiter at an altitude of $481 \mathrm{~km}$ ( $260 \mathrm{n}$ mile) and retrieved at $333 \mathrm{~km}$ ( $180 \mathrm{n}$ mile). Since near-Earth space exposure of 5.8 years for any retrieved experiment has never before been achieved, even the very limited results from this experiment with toughened composites provide an indication of their future applicability to space structures.

\section{Test Procedure}

The tensile dumbbell-shaped specimens are each about $183 \mathrm{~mm}$ in overall length with test-section width about $20 \mathrm{~mm}$, as shown in Fig. 1. All specimens with intermittent interlaminar bonding

Received March 18, 1993; revision received Aug. 19, 1993; accepted for publication Nov. 17, 1993. Copyright (C) 1994 by the American Institute of Aeronautics and Astronautics, Inc. All rights reserved.

*Professor of Mechanical Engineering, 2250 G. G. Brown Laboratory. consist of eight layers of prepreg unidirectional T300 graphite tape with 5208 epoxy, plus seven layers of $7-\mu$ m-thick Mylar $^{\circledR}$, and are about $1.1 \mathrm{~mm}$ thick. For this study, orientations of the graphite cross ply were either \pm 20 or \pm 45 deg relative to the tensile axis. The prepreg composite of T300 graphite with 5208 epoxy was Narmco Lot 50548470 , batch 20 , roll 20 , having density of $142.2 \mathrm{~g} / \mathrm{m}^{2}$ and $67.4 \%$ filament. The Mylar used contains evenly spaced holes of $1.1-\mathrm{mm}$ diam in a matrix spaced appropriately for the percentage of contact desired. For specimens with $0 \%$ contact, Teflon ${ }^{\circledR}$ was sprayed on each of the contacting layers of prepreg prior to curing so as to prevent interlaminar bonding. Specimens for $100 \%$ contact were cured with nothing between adjacent layers. Vacuum curing of all specimens was in accordance with the manufacturer's specifications. Using steel friction grips, each specimen was tested in tension initially for elastic modulus at moderate loads and a crosshead speed of $0.5 \mathrm{~mm} / \mathrm{min}$, then later fractured in tension to measure its strength as the maximum stress (load/net area) during the test. (Elastic modulus is the ratio of incremental stress to incremental strain at stresses well below the fracture stress, that is, where the stress-strain curve is virtually a straight line.)

The fracture-toughness compact tension specimens are about $190 \mathrm{~mm}$ long and about $70 \mathrm{~mm}$ wide overall, as shown in Fig. 2. A narrow $27.5-\mathrm{mm}$ transverse slot is machined on the initiation side, and a $22.5-\mathrm{mm} 60-\mathrm{deg}$ notch is cut out on the termination side to control out-of-plane buckling, with a net test-section width of approximately $20 \mathrm{~mm}$. Each specimen with intermittent interlaminar bonding consists of eight layers of prepreg plus seven layers of Mylar in the same manner as for the tensile-modulus specimens. The $100 \%$ and $0 \%$ contact specimens have likewise the same layup as for the tensile-modulus specimens (Table 1). Each specimen is mounted in a loading frame as shown in Fig. 3. Each half of the frame is made of 8-mm-thick structural steel and is loaded as shown by the arrows in Fig. 3. A matrix of compression screws to secure the specimen, not shown here, was found to be necessary to prevent slippage of the specimen.

Because the compact tension specimen permits slow stable fracture to occur, the load-displacement curve can be recorded, in accordance with the Gurney method, ${ }^{3,4}$ at a crosshead speed of $0.5 \mathrm{~mm} / \mathrm{min}$. In this case we made the arbitrary assumption that all work done following an $80 \%$ drop from the maximum load is neglected; in fact, each specimen would continue to absorb energy until complete separation is achieved, so this assumption leads to a conservative measure of fracture energy. This additional energy would normally be expected to exceed the elastic energy that would be given up by the specimen if it could return to its initial displacement in accordance with the principle of the Gurney method. The net work done divided by the apparent minimum fracture area (specimen thickness times increase in crack length) is thus the fracture toughness $R$, where the stress intensity factor $K_{\mathrm{Ic}}=(E R)^{\frac{1}{2}}$. Note that $K_{\mathrm{I} c}$ is not the plane-strain critical stress intensity factor, but the mode-I 
Table 1 All data

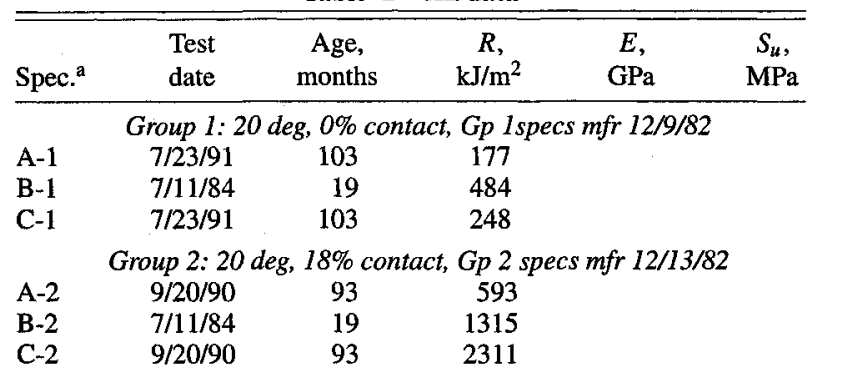

Group 3: 20 deg, 100\% contact, Gp 3 specs $m$ fr 12/7/82 $7 / 23 / 91 \quad 104 \quad 165$

$\begin{array}{llll}\text { B-3 } & 7 / 11 / 84 & 19 & 241\end{array}$

C-3 7/23/91 $104 \quad$ no result

Group 4: $45 \mathrm{deg}, 0 \%$ contact, Gp 4 specs $m f r$ 12/15/82

A-4

B-4

$7 / 23 / 91 \quad 103$

839

$19-1116$

$7 / 23 / 91 \quad 103 \quad 1200$

Group 5: 45 deg, $36 \%$ contact, Gp 5 specs $m$ fr 12/17/82 $9 / 20 / 90 \quad 93 \quad 1410$

$\begin{array}{llll}\text { B-5 } & 7 / 11 / 84 & 19 & 1528\end{array}$

$\begin{array}{llll}\text { C-5 } & 9 / 20 / 90 & 93 & 2540\end{array}$

Group 6: 45 deg, 100\% contact, Gp 6 specs mfr 12/16/82 $7 / 23 / 91 \quad 103 \quad 400$

$\begin{array}{lrrr}\text { B-6 } & 7 / 11 / 84 & 19 & 890\end{array}$

$\begin{array}{llll}\text { C-6 } & 7 / 23 / 91 & 103 & 886\end{array}$

A-7

Group 7: 20 deg, $0 \%$ contact, Gp 7 specs mfr 12/3/82

$\begin{array}{lll}7 / 16 / 91 & 103 & 80.9\end{array}$

$7 / 18 / 91 \quad 103$

$6 / 9 / 84 \quad 18$

$6 / 22 / 84 \quad 19$

$7 / 16 / 91 \quad 103$

116

$7 / 18 / 91 \quad 103$

62.2

Group 8: 20 deg, $18 \%$ contact, Gp 8 specs mfr 12/9/82

\begin{tabular}{lcrcc} 
A-8 & $9 / 21 / 90$ & 93 & 186 & \\
A-8 & $10 / 9 / 90$ & 94 & & 344 \\
B-8 & $6 / 9 / 84$ & 18 & 87.9 & \\
B-8 & $6 / 22 / 84$ & 18 & 111 & 285 \\
C-8 & $9 / 21 / 90$ & 93 & & 336 \\
C-8 & $10 / 9 / 90$ & 94 & 68.5 & \\
\multicolumn{5}{c}{ Group $9: 20$ deg, $18 \%$ contact, Gp 9 specs } \\
A-9 & $7 / 16 / 91$ & 103 & & 365 \\
A-9 & $7 / 18 / 91$ & 103 & 67.6 & \\
B-9 & $6 / 9 / 84$ & 18 & & 324 \\
B-9 & $6 / 22 / 84$ & 19 & 45.6 & \\
C-9 & $7 / 16 / 91$ & 103 & & 290 \\
C-9 & $7 / 18 / 91$ & 103 &
\end{tabular}

Croup 10: 20 deg, $100 \%$ contact, Gp 10 specs $m$ fr 12/5/82

A-10

A-10

B-10 $7 / 16 / 91$

103

$7 / 18 / 91$

$6 / 9 / 84$

$6 / 22 / 84$

103

18

111

$7 / 16 / 91$

103

97.2

40.9

Group 11: 45 deg, 0\% contact, Gp 11 specs mfr 12/16/82

A-11

A-11

B-11

B-11

C-11

$7 / 16 / 9$

$7 / 18 / 91$

103

$6 / 9 / 84$

$6 / 22 / 84$

$7 / 16 / 91$

18

18

103

$7 / 18 / 91$

103

10.1

17.5

Group 12: 45 deg, $36 \%$ contact, Gp 12 specs $m f r$ 12/18/82

A-12

A-12

B-12

B-12

C-12

C-12

A-13 $7 / 16 / 91$

$7 / 18 / 91$

$6 / 9 / 84$

$6 / 22 / 84$

$7 / 16 / 91$

103

103

18
18

$7 / 18 / 91$

103

103

Group 13: 45 deg, 36\% contact, Gp specs mfr 12/19/82

$\begin{array}{ll}9 / 21 / 90 & 93 \\ 10 / 9 / 90 & 94\end{array}$

93

18
7.07

17

9.3

95

94.6

114

81

56.7

78.5

Table 1 (Continued) All data

\begin{tabular}{|c|c|c|c|c|c|}
\hline Spec. ${ }^{\mathrm{a}}$ & $\begin{array}{l}\text { Test } \\
\text { date }\end{array}$ & $\begin{array}{l}\text { Age, } \\
\text { months }\end{array}$ & $\begin{array}{c}R, \\
\mathrm{~kJ} / \mathrm{m}^{2}\end{array}$ & $\begin{array}{c}E, \\
\mathrm{GPa}\end{array}$ & $\begin{array}{r}S_{u}, \\
\mathrm{MPa}\end{array}$ \\
\hline C-13 & $9 / 21 / 90$ & 93 & & 17.1 & \\
\hline C-13 & $10 / 9 / 90$ & 94 & & & 84.7 \\
\hline \multicolumn{6}{|c|}{ Group 14: 45 deg, 100\% contact, Gp 14 specs mfr 12/17/82 } \\
\hline A-14 & $7 / 16 / 91$ & 103 & & 12.2 & \\
\hline A-14 & $7 / 18 / 91$ & 103 & & & 115 \\
\hline B-14 & $6 / 9 / 84$ & 18 & & 16.1 & \\
\hline B-14 & $6 / 22 / 84$ & 18 & & & 127 \\
\hline C-14 & $7 / 16 / 91$ & 103 & & 9.68 & \\
\hline C-14 & $7 / 18 / 91$ & 103 & & & 127 \\
\hline
\end{tabular}

Group 15: 20 deg, 36\% contact, Gp 15 specs $m$ fr 12/13/82

\begin{tabular}{lllll} 
A-15 & $9 / 21 / 90$ & 93 & 84 & \\
A-15 & $10 / 9 / 90$ & 94 & 124 & 253 \\
B-15 & $6 / 9 / 84$ & 18 & & 292 \\
B-15 & $6 / 22 / 84$ & 18 & 125 & \\
C-15 & $9 / 21 / 90$ & 93 & & 269 \\
C-15 & $10 / 9 / 90$ & 94 & & \\
\hline
\end{tabular}

${ }^{a}$ Specimen prefixes, $\mathrm{A}, \mathrm{B}$, and $\mathrm{C}$ represent the following: $\mathrm{A}, \mathrm{LDEF}$ flight exposure; $B$, no exposure, zero-time testing; $C$, ground storage, full-time testing.

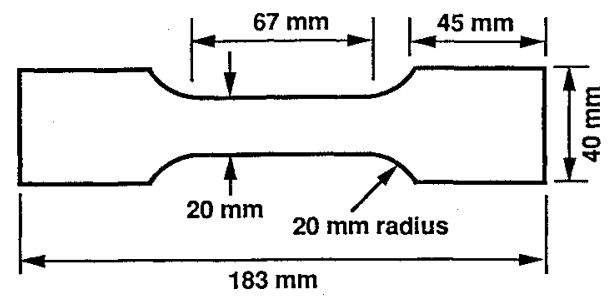

Fig. 1 Tensile specimen.

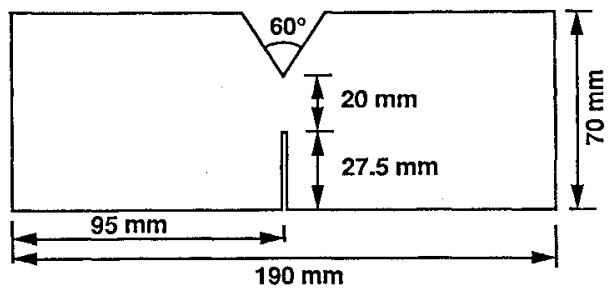

Fig. 2 Fracture-toughness specimen.

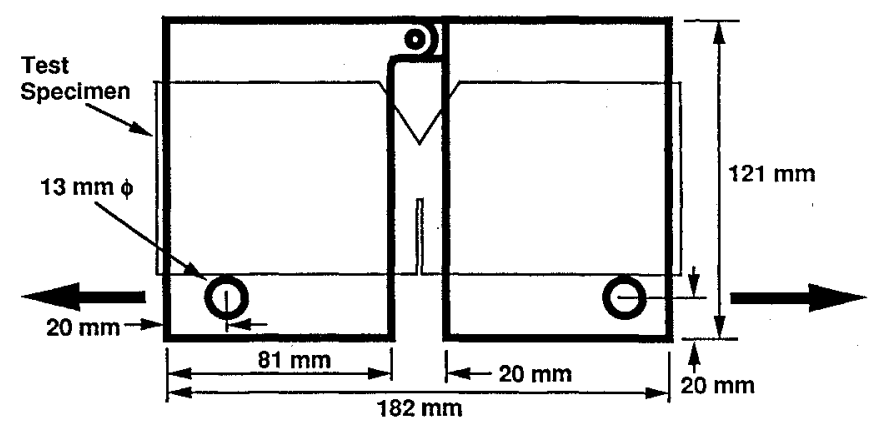

Fig. 3 Fracture-toughness test frame.

critical stress intensity factor. With the large values of toughness measured, the ratio of stress intensity factor to yield strength (in this case the fracture stress), upon which the radius of the plastic region depends, would mandate thicknesses one to three orders of magnitude greater than the subject specimens in order to achieve mostly plane strain conditions. Thus the results obtained here for plane stress are meaningful for the range of thicknesses measured, as well as foreseeable thicknesses that might be used in actual structures.

For each of the two classes of specimens, tensile and fracture toughness, the cross-ply angle and the fraction (percent) of contact between adjacent plies are varied. The interlaminar contact fraction is controlled by the spacing of 1.1-mm-diam holes in the Mylar sheet; this establishes the fraction of the total area of adjacent plies that are in contact. 


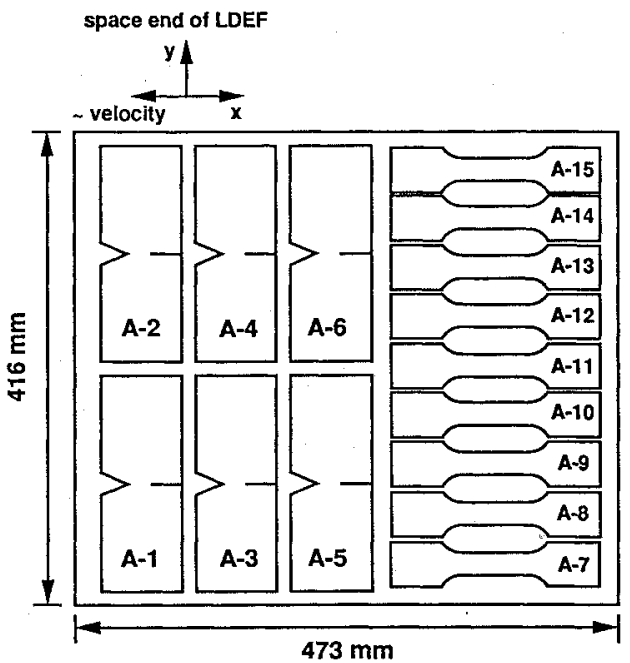

Fig. 4 Orientation of experiment A0019 test frame on tray D12 on LDEF.

\section{Experiment Location and Exposure}

The experiment was located on LDEF in tray D12, which was oriented so that the vector normal to the plane of the tray was 82 deg from the velocity vector. The layout of the 15 specimens, and their orientation with respect to space and the approximate velocity vector of LDEF, are shown in Fig. 4. All specimens were held in place with thin aluminum strips bolted to the test frame, not shown in the sketch. During the mission the experiment tray received ${ }^{5}$ a full-spectrum total solar fluence of $33.5 \mathrm{GJ} / \mathrm{m}^{2}$, and a total solar fluence in the $0.2-0.4-\mu \mathrm{m}$ band of $2.68 \mathrm{GJ} / \mathrm{m}^{2}$. This exposure was approximately $47 \%$ of the exposure received by the space-facing end of LDEF and approximately $61 \%$ of the exposure received by the leading edge of LDEF.

The total atomic-oxygen fluence on the experiment tray at the end of the mission was $12.0 \times 10^{24}$ atoms $/ \mathrm{m}^{2}$, which was approximately $14 \%$ of the fluence experienced by the leading edge of LDEF. ${ }^{5}$ Of particular importance here is that atomic oxygen produced erosion in this experiment only in the surface epoxy and caused no loss of graphite filaments.

In a cursory examination limited to micrometeoroids of diameter greater than $0.3 \mathrm{~mm}, 215$ impact features were observed ${ }^{6}$ in tray D12, of which the present experiment tray comprised $\frac{1}{6}$ of the total area. Of these impacts, 189 were 0.3 to $0.5 \mathrm{~mm}$ in diameter and 26 were larger than $0.5 \mathrm{~mm}$ in diameter. The largest observed impact was $1.6 \mathrm{~mm}$ in diameter. Several apparent damage indications were observed on graphite-epoxy specimens, but replicas of these areas failed to provide clear evidence of the cause of this damage. Examination of replicas of a very small fraction of the aluminum surfaces from the present experiment in the field emission microscope revealed large numbers of impact craters as small as $0.1-\mu \mathrm{m}$ diameter, leading to an estimated total number of impact craters larger than $0.1 \mu \mathrm{m}$ on the present experiment of the order of 2000 to 10,000 . Because the number of micrometeoroid craters varies inversely with diameter, most of the impacts were very small and thus unlikely to have penetrated suffciently to lead to significant structural damage in the graphite-epoxy specimens.

\section{Results}

All specimens were manufactured in December 1982, in preparation for delivery of the flight specimens to NASA Langley Research Center the following spring for vibration testing and installation on LDEF. All specimens for each of the 15 groups were cured at the same time from the same batch. LDEF was launched in April 1984, approximately 16 months after manufacture of the specimens, and retrieved in January 1990. The three sets of specimens were designated as:

Set A: Flight specimens, to be flown on board LDEF

Set B: Zero-time specimens, to be tested at the time of the launch of LDEF.
Set C: Total-time ground specimens stored in an air-conditioned and heated building at approximately $20^{\circ} \mathrm{C}$, to be tested after the flight along with set $\mathrm{A}$.

Six fracture-toughness specimens (group numbers 1-6) and nine tensile specimens (group numbers 7-15), of varying layup angle and percentage of contact, were manufactured for each of the three sets. Complete descriptions of the characteristics of each group of specimens, date of manufacture, date of testing, and results are compiled in Table 1 .

\section{Mechanical Test Results}

Substantial changes in mechanical properties of the ground control specimens occurred during the 100 months of the experiment. Our past experience with composite specimens of this same type had shown some modest scatter in results, but we had never tested specimens that were more than a few months old. In the present program, even the zero-time specimens, set $B$, were approximately 18 months old when tested, and the rest of the specimens were about 100 months old. The scatter in results between the zero-time specimens (set B) and the total-time ground specimens (set C) was therefore unanticipated. One study on aging effects in graphite-epoxy ${ }^{7}$ at $121^{\circ} \mathrm{C}$ over almost exactly the same time duration $(50 \mathrm{kh})$ as the LDEF mission showed no loss in $177^{\circ} \mathrm{C}$ strength of unidirectional composites, and approximately $40 \%$ loss in $177^{\circ} \mathrm{C}$ strength for \pm 45 deg cross plies.

The effect of thermal cycling from orbiting on the coefficient of thermal expansion of unidirectional graphite-epoxy was simulated in a study, ${ }^{8}$ which concluded that cracking observed at the filament-matrix interface led to an increase in the coefficient of thermal expansion, which became more severe with increase in the test temperature and duration of the test. Thus the influence of possible interfacial cracking from thermal cycling introduces yet another environmental factor that must be considered.

The results demonstrate that, in general, partial contact produces the highest values of toughness, as would be expected from the basic mechanism of intermittent bonding. Thus the toughness for 18 and $36 \%$ contact is higher than for $0 \%$ contact, and much higher than for $100 \%$ contact. The effect of interlaminar treatment on this graphite-epoxy has already been covered elsewhere ${ }^{2}$ and was not an objective of the present study. As anticipated, the toughness for 18 and $36 \%$ contact is higher than for $0 \%$ contact, and much higher than for $100 \%$ contact.

\section{$\pm 20-$ deg Cross Ply, 100\% Contact}

Figures 5-7 contrast the properties of the \pm 20 -deg $100 \%$-contact specimens before and after flight. Data on the toughness and strength of total-time ground specimens are not available. For the $100 \%$ contact specimens, the toughness is low for both zero-time and flight specimens compared with specimens having less than $100 \%$ contact

\section{\pm 20 -deg Cross Ply, 18\% Contact}

Figures 8-10, for \pm 20 -deg $18 \%$-contact specimens, show much higher toughness than for the $100 \%$ specimens, higher modulus, and somewhat lower strength. Only the toughness drops significantly after flight exposure.

\section{$\pm 45-$ deg Cross Ply, 100\% and 36\% Contact}

Likewise, Figs. 11-16 show results for \pm 45 -deg specimens, 100 and $36 \%$ contact. Because of the increased angle of the cross plies, strength and modulus drop markedly, in contrast to the \pm 20 -deg specimens. Again, the toughness of the $36 \%$ specimens is higher than that of the $100 \%$ specimens, and the flight toughness for the $36 \%$ specimens is virtually the same as the zero-time toughness Similar comparisons can be made for the other sets of specimens; since the overall balance of properties of the $0 \%$ contact specimens is not as good as for either partial or $100 \%$ contact, they are poor candidates for consideration as structural materials.

\section{Toughness of Flight Specimens}

In every case, the toughness of the flight specimens was less than that of the zero-time and the ground control total-time specimens; this suggests degradation from exposure. The toughness of all flight 


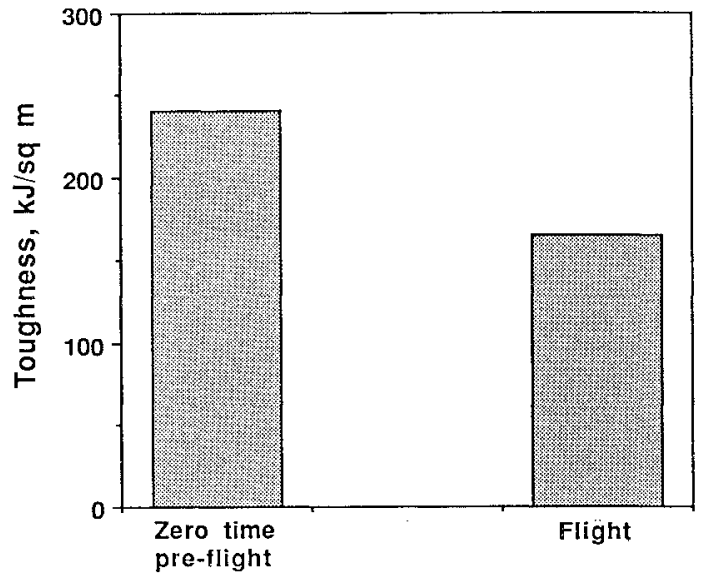

Fig. 5 Toughness of specimens with \pm 20 -deg cross ply, $100 \%$ contact.

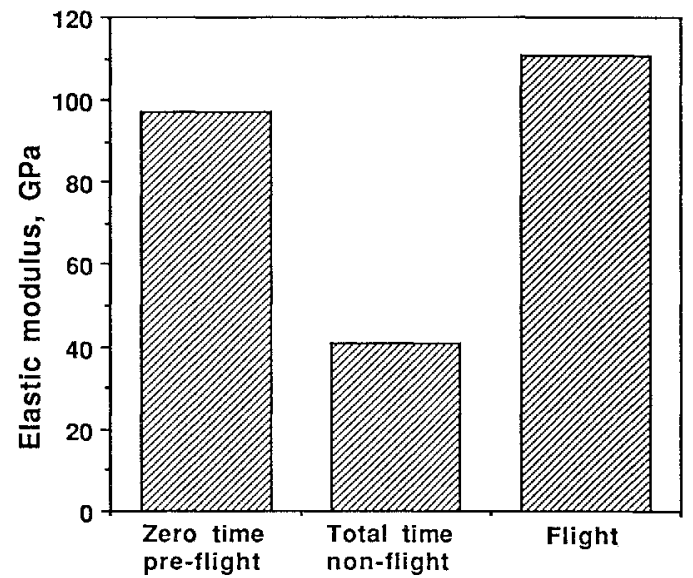

Fig. 6 Elastic modulus of specimens with \pm 20 -deg cross ply, $100 \%$ contact.

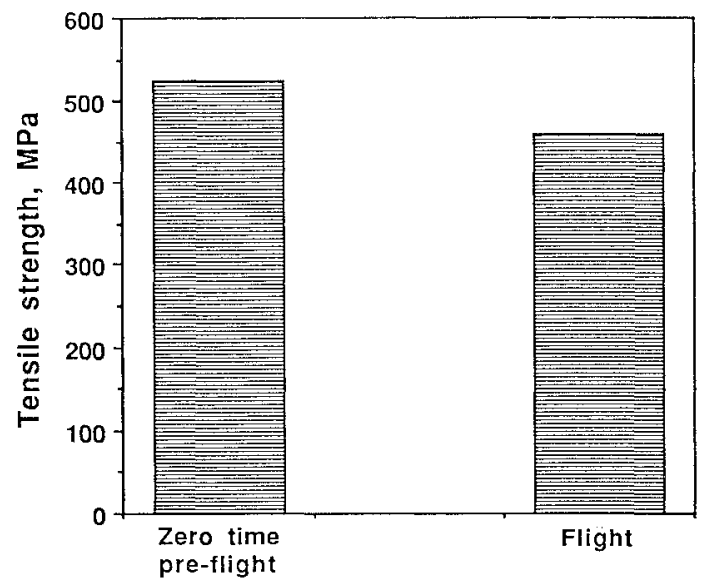

Fig. 7 Tensile strength of specimens with \pm 20 -deg cross ply, $100 \%$ contact.

specimens is shown in Fig. 17. As already noted above, we have no explanation for the increases of toughness with time of most of the ground control total-time specimens and, for \pm 20 - $\operatorname{deg} 0 \%$ specimens, a marked decrease in toughness with time. Thus we cannot evaluate the effect of exposure alone, considering the already large effect of time.

Modulus of Flight Specimens

Figure 18 shows the elastic modulus of all flight specimens. The \pm 45 -deg specimens are all of low modulus as a consequence of the large angle of the filaments with respect to the tensile direction; all of the \pm 20 -deg specimens show several times the modulus of the \pm 45 -deg specimens. That one of the \pm 20 -deg $18 \%$ specimens shows much higher modulus than the corresponding $100 \%$-contact

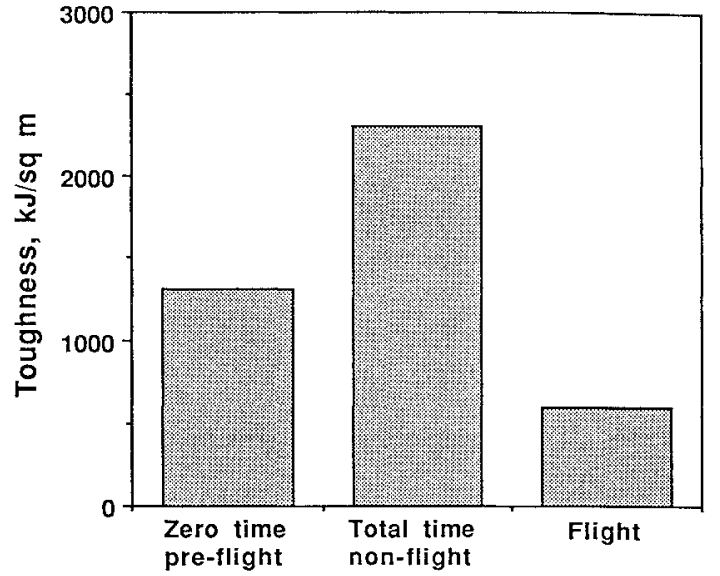

Fig. 8 Toughness of specimens with \pm 20 -deg cross ply, $18 \%$ contact.

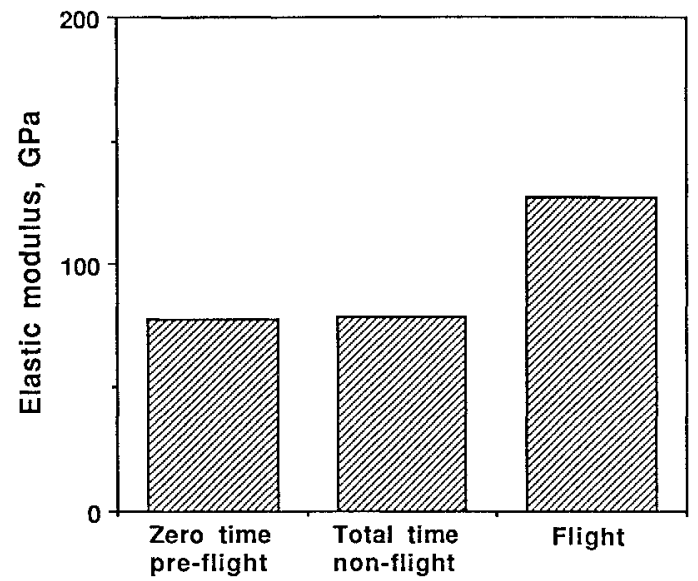

Fig. 9 Elastic modulus of specimens with \pm 20 -deg cross ply, $18 \%$ contact. Averages of specimens of groups 8 and 9.

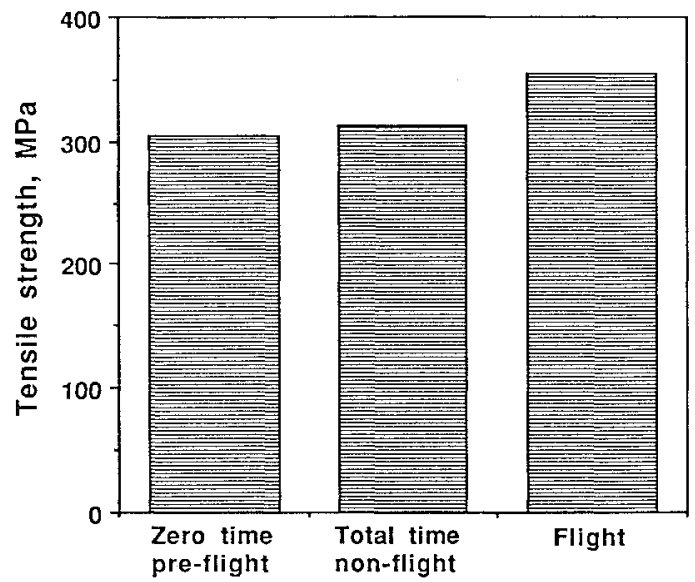

Fig. 10 Tensile strength of specimens with \pm 20 -deg cross ply, $18 \%$ contact. Averages of specimens of gromps 8 and 9.

specimen suggests that the \pm 20 -deg $18 \%$ datum may be the result of an inaccurate measurement. The scatter in modulus of flight specimens that is demonstrated in Fig. 18 appears to follow no consistent pattern, and the very limited number of tests precludes further conclusions. The testing procedure for measuring the modulus is rather critically dependent on control of specimen slippage, with scatter observed in repeated tests; thus we have used average values here. The widely different values of modulus in groups 8 and 9 , which have the same layup, demonstrate this problem.

\section{Strength of Flight Specimens}

The strength of all flight specimens (Fig. 19) shows a similar difference between the \pm 45 -deg specimens and the \pm 20 -deg specimens. As expected, the $100 \%$-contact specimens for both layup 


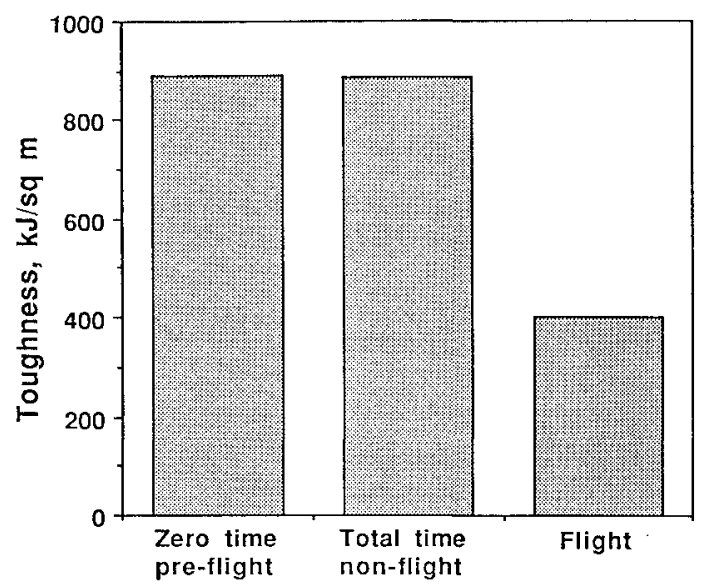

Fig. 11 Toughness of specimens with \pm 45 -deg cross ply, $100 \%$ contact.

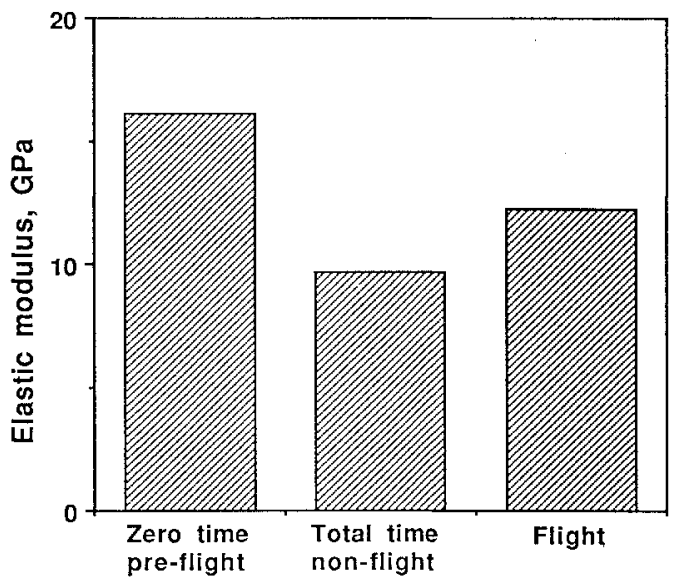

Fig. 12 Elastic modulus of specimens with \pm 45 -deg cross ply, $100 \%$ contact.

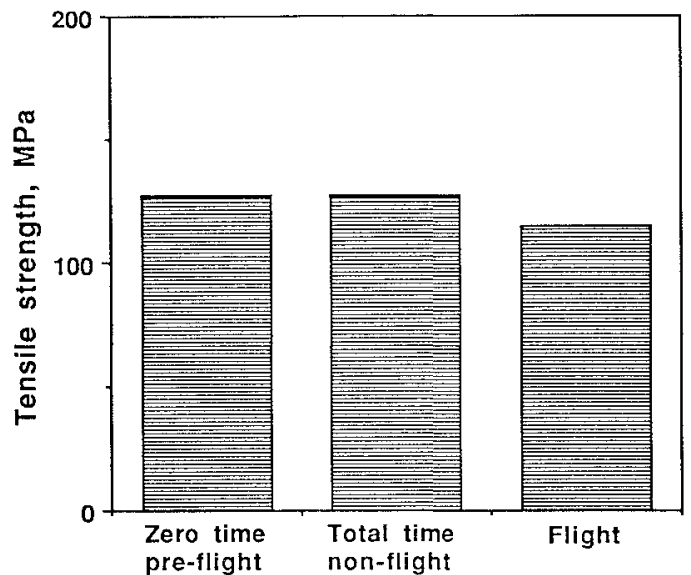

Fig. 13 Tensile strength of specimens with \pm 45 -deg cross ply, $100 \%$ contact.

angles show the highest strengths. Measurement of strength of these composites is more precise than measurement of toughness or modulus, as can be noted by the closeness of values for groups 8 and 9 . The scatter of the ground specimens is less for the strength specimens, and flight specimens are in every case but one (group 9 $\pm 20 \mathrm{deg}, 18 \%$ ) lower in strength than total-time control specimens. We may conclude that flight exposure led to some degradation in strength in almost all cases.

\section{Other Observations}

We noted some apparently anomalous indentations on our aluminum frame, which we have reported elsewhere. ${ }^{9,10}$ We believe now, after further systematic examination of ground control and flight-tray clips, that these observations represent artifacts somehow

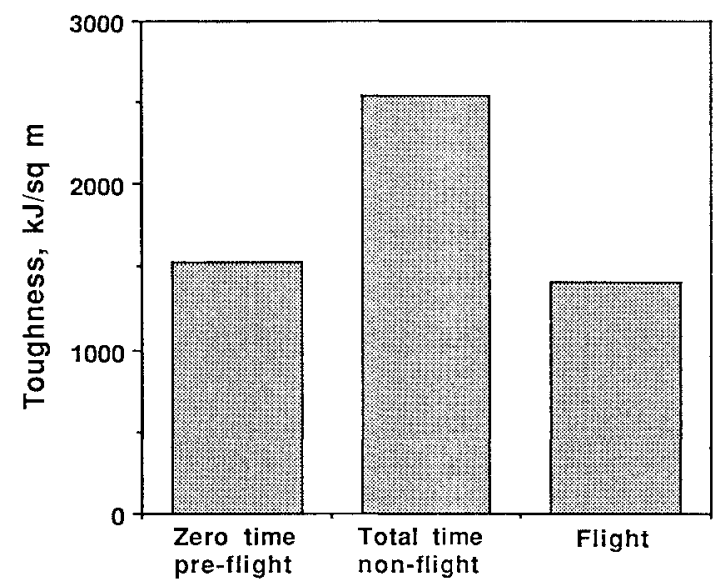

Fig. 14 Toughness of specimens with \pm 45 -deg cross ply, $36 \%$ contact.

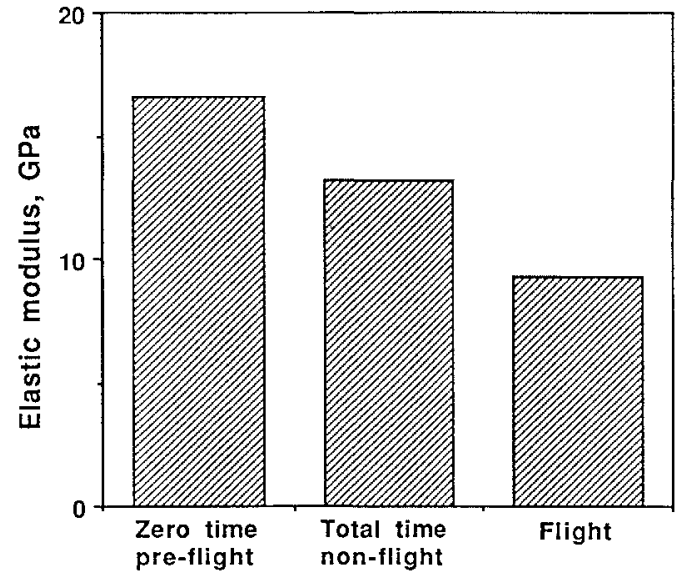

Fig. 15 Elastic modulus of specimens with \pm 45 -deg cross ply, $36 \%$ contact. Averages of specimens of groups 12 and 13 .

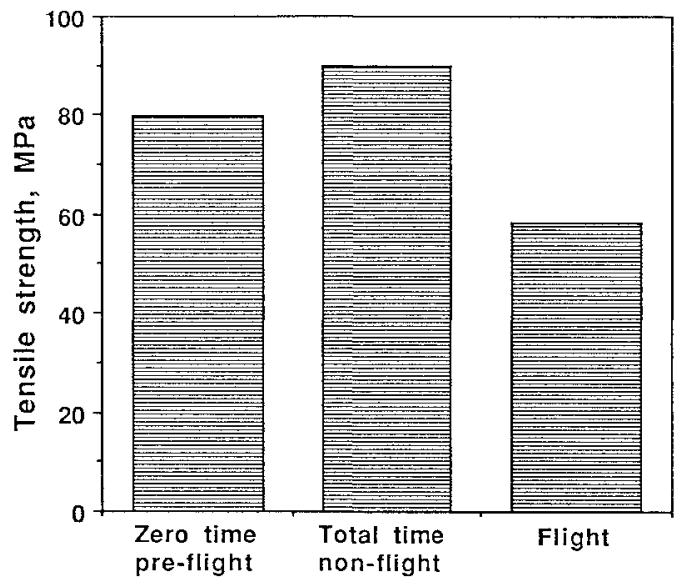

Fig. 16 Tensile strength of specimens with \pm 45 -deg cross ply, 36\% contact. Averages of specimens of groups 12 and 13.

resulting from techniques of fabrication, although we still have not established their origins.

Wahl maximum-temperature sensors were located on the outside (exposed) face of each of the specimens. These sensors indicate the maximum temperature reached during ground storage, launch, flight, retrieval, and postflight storage, in increments of $11^{\circ} \mathrm{C}$. The temperatures indicated upon retrieval of the experiment are given in Table 2.

From Fig. 4 it is apparent that specimens A-4 through A-7 have no special location or orientation with respect to the experiment panel that would explain the lower observed maximum temperature, and no other LDEF experiment in the vicinity is likely to have led to the observed differences. Thus we may conclude that the maximum 
Table 2 Maximum external temperatures

\begin{tabular}{lccccc}
\hline Specimen & Temp. ${ }^{\circ} \mathrm{C}$ & Specimen & Temp. ${ }^{\circ} \mathrm{C}$ & Specimen & Temp. ${ }^{\circ} \mathrm{C}$ \\
\hline A-1 & 93 & A-6 & 82 & A-11 & 93 \\
A-2 & 93 & A-7 & 82 & A-12 & 93 \\
A-3 & 93 & A-8 & 93 & A-13 & 93 \\
A-4 & 82 & A-9 & 93 & A-14 & 93 \\
A-5 & 82 & A-10 & 93 & A-15 & 93 \\
\hline
\end{tabular}

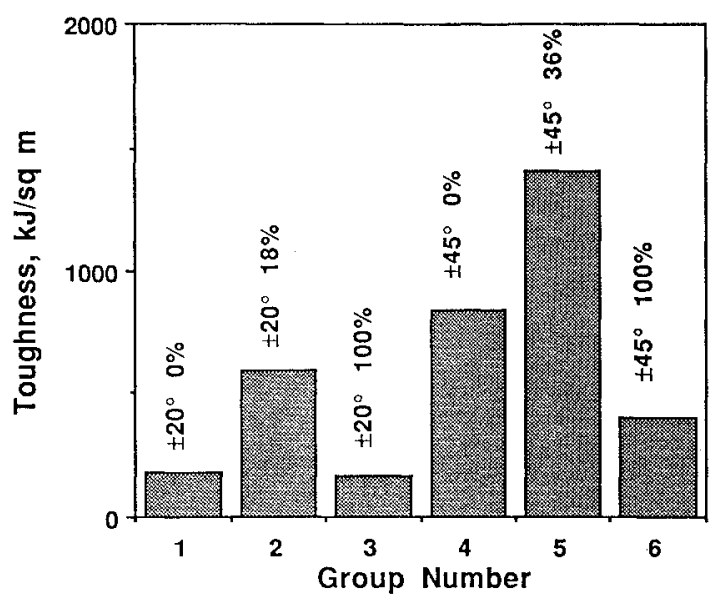

Fig. 17 Toughness of flight specimens.

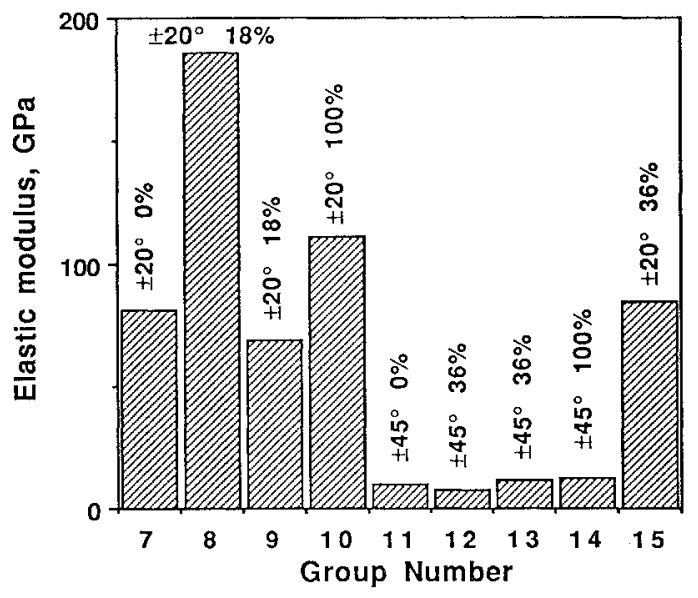

Fig. 18 Elastic modulus of flight specimens.

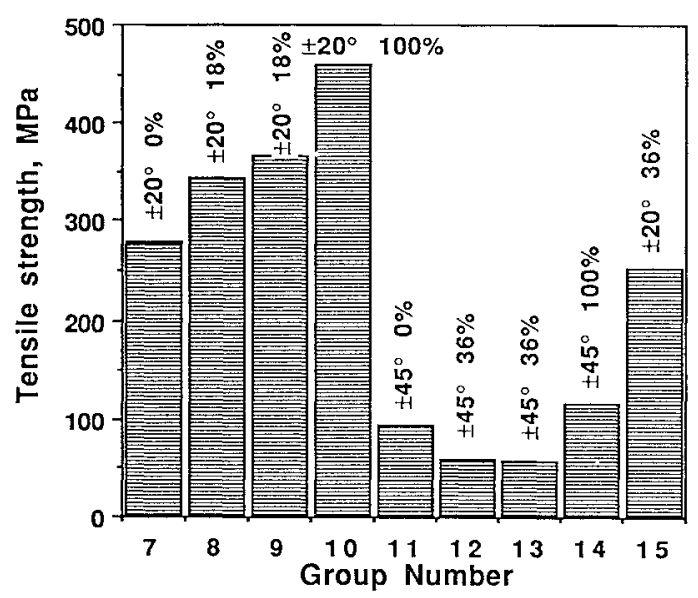

Fig. 19 Tensile strength of flight specimens.

external temperature reached was close to $93^{\circ} \mathrm{C}$, with some sensors indicating $93^{\circ} \mathrm{C}$ and others indicating the next lower temperature, $82^{\circ} \mathrm{C}$.

Wahl maximum-temperature sensors were located on the under side (unexposed) surface of the test frame at nine locations. Upon retrieval, all of these sensors read $82^{\circ} \mathrm{C}$.

\section{Concluding Remarks}

The following experimental results were noted:

1) Marked degradation from exposure, by a factor of roughly two from the control specimens, is observed in every one of the six toughness specimens.

2) Except for the group- 1 specimen ( \pm 20 -deg, $0 \%$ contact), the toughness of the other four control specimens increased during the 100 or so months since manufacture. Although an observation that four out of five specimens increased in toughness is significant, the limited amount of this increase probably lies within the range of scatter for the test.

3) The elastic modulus of the flight specimens varied rather widely from the control specimens for the same life, both higher and lower. In six of the nine specimens, the flight modulus was lower than the zero-time modulus; in four of the nine specimens, the flight modulus was lower than the total-time ground specimens. Some of this variation is surely experimental scatter, but we have no way to establish its extent.

4) In most cases, the elastic modulus of the control specimens either remained about the same or degraded during the experiment. In no case did it increase significantly.

5) The strength of the flight specimens ranged from moderate increase to moderate decrease, except for group 7 ( $\pm 20 \mathrm{deg}, 0 \%$ contact), which was about half of the initial strength. In every specimen except \pm 20 deg with $18 \%$ contact, the strength of the flight specimens was less than that of the total-time ground specimens.

6) The change in strength of the control specimens ranged from moderate increase to moderate decrease. Even with the better precision of the strength results, this modest variation is probably attributable to scatter.

7) Substantial differences are observed in the behavior of specimens having different cross-ply angles and fraction of interlaminar contact.

8) In general, the $0 \%$ - and $100 \%$-contact layups produced poorer combinations of postflight properties than partial-contact layups with the same cross-ply arrangement.

From these experimental results the following conclusions are drawn:

1) With the proper selection of layup (see discussion of \pm 20 deg and $18 \%$ contact below), and also for choices of layups not included in this experiment, toughened graphite-epoxy composites can be used for extended exposure, at least in near-Earth orbit, for periods of the order of 5 years without degradation to intolerable levels of toughness, elastic modulus, and strength. This assumes that suitable coating or protection from solar exposure and atomic oxygen is provided; neither of these problems was severe in our test, because of the orientation of the test panel.

2) The single best combination of acceptable properties of toughness, elastic modulus, and strength in uniaxial tension after flight exposure is achieved for the layup of groups 2, 8, and 9: $\pm 20 \mathrm{deg}$, $18 \%$ contact. These results are shown in Figs. 8-10. Although the toughness dropped to $593 \mathrm{~kJ} / \mathrm{m}^{2}$, this is still an entirely acceptable value, and both the elastic modulus and the tensile strength remained essentially constant as a result of the 5.8-y near-Earth space exposure.

\section{Acknowledgments}

This work was performed under National Aeronautics and Space Administration Langley Research Center Grant NAS117008. We are grateful for the assistance, cooperation, and support of Lenwood Clark, James Jones, and the entire LDEF staff. William H. Durrant designed the basic experiment panel and supervised its construction. Stephen B. Culp manufactured the specimens. Both men participated in the testing. Without them this experiment would never have taken off, and we are grateful.

\section{References}

${ }^{1}$ Marston, T. U., Atkins, A. G., and Felbeck, D. K., "Interfacial Fracture Energy and the Toughness of Composites," Journal of Materials Science, Vol. 9, No. 3, 1974, pp. 447-455. 
${ }^{2}$ Jea, L.-C., and Felbeck, D. K., "Increased Fracture Toughness of Graphite-Epoxy Composites through Intermittent Interlaminar Bonding," Journal of Composite Materials, Vol. 14, July 1980, pp. 245-259.

${ }^{3}$ Gurney, C., and Hunt, J., "Quasi-static Crack Propagation," Proceedings of the Royal Society of London, Series A, Vol. 299, No. 1459, 1967, pp. $508-524$.

${ }^{4}$ Felbeck, D. K., and Atkins, A. G., Strength and Fracture of Engineering Solids, Prentice-Hall, Englewood Cliffs, NJ, 1984, pp. 333-335.

${ }^{5}$ Bourassa, R. J., Gillis, J. R., and Rousslang, K. W., "Atomic Oxygen and Ultraviolet Radiation Mission Total Exposures for LDEF Experiments," $L D E F-69$ Months in Space, edited by Arlene S. Levine, NASA CP 3134, Part 2, June 2-8, 1991, pp. 643-661.

${ }^{6}$ LDEF Meteoroid and Debris Special Investigation Group, "Meteoroid and Debris Impact Features Documented on the Long Duration Exposure Facility," NASA Lyndon B. Johnson Space Center, Houston, TX, Planetary
Science Branch Pub. \#84, JSC \#24608, Aug. 1990, pp. 273-276.

${ }^{7}$ Kerr, J. R., and Haskins, J. F., "Effects of $50,000 \mathrm{~h}$ of Thermal Aging on Graphite/Epoxy and Graphite/Polyimide Composites," AIAA Journal, Vol. 22, No. 1, 1984, pp. 96-102.

${ }^{8}$ Morris, W. L., James, M. R., and Inman, R. V., "Accelerated Aging of the Thermal Expansion of Unidirectional Graphite/Epoxy Composites by Thermal Fatigue," Journal of Engineering Materials and Technology, Vol. 111, No. 4, Oct. 1989, pp. 331-337.

${ }^{9}$ Felbeck, D. K., and Durrant, W.H., "Repetitive Orbital Damage," Nature, Vol. 347, Sept. 27, 1990, p. 341.

${ }^{10}$ Felbeck, D. K., Author's response to Scientific Correspondence, Nature, Vol. 352, July 25, 1991, p. 289.

R. K. Clark Associate Editor
Electric Propulsion FOR SPACE SySTEMS

July 8-9, 1995

San Diego, CA

Continuing Education Short Course Offered in Conjunction with the AIAA/ASME/SAE/ASEE

31 st Joint Propulsion Conference and Exhibit

information call or

FAX Johnnie White

Phone: 202/646-7447

FAX: 202/646-7508 ractical electric thrusters with long lives and the electrical-power systems required to sustain them have produced a spacecraft-propulsion-system revolution. This course is designed to give you a solid background of the operating principles, performance characteristics, and design features from each of the three classes of electric thrusters.

\section{WHO SHOULD ATTEND}

Engineers and scientists who design spacecraft systems and missions, particularly those involved with station keeping, station movement, and the propulsion systems required to transport space systems to their operating stations.

\section{HOW YOU WILL BENEFIT FROM THIS COURSE}

- Understand the principles of operation for thrusters from each of the classes of electric thrusters.

- Discover the benefits of mission analysis and technology trades.

- Gain an understanding of propulsion system integration issues.

- Gain a solid background in the physics governing the operation and perfor mance of electric propulsion systems.

- Discover the performance gains achievable with the use of electric propulsion.

\author{
INSTRUCTORS \\ Led by Dr. Paul J. Wilbur Colorado State University
}

For more detailed

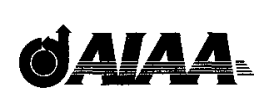

American Institute of Aeronautics and Astronautics 